\title{
Molecular diagnostic of some nematode species infecting ruminants in Egypt
}

\author{
Nasr M. Elbahy ${ }^{1}$, Reda E. Khalafalla ${ }^{2 *}$, \\ ${ }^{1}$ Department of Parasitology, Faculty of Veterinary Medicine, Sadat City University, Minufiya, Egypt \\ ${ }^{2}$ Department of Parasitology, Fac. Vet. Med., Kafrelsheikh University, Kafr El-Sheikh, Egypt \\ *Corresponding author E-mail: redabast@hotmail.de
}

Copyright $\odot 2014$ Reda E. Khalafalla, Nasr M. Elbahy. This is an open access article distributed under the Creative Commons Attribution License, which permits unrestricted use, distribution, and reproduction in any medium, provided the original work is properly cited.

\begin{abstract}
Molecular techniques are utilized for the diagnosis of parasitic diseases and identification of parasites to enhance the development of specific antigens for serological tests and studying immune response in the patients.

In the present study, nematode parasites were Trichuris ovis which were recovered from goats and Trichuris ovis, Haemonchus contortus, and Strongyloides papillosus were recovered from sheep as well Toxocara vitullorum from buffaloes and Toxocara vitullorum from cattle. All samples were checked with 3 different primers by the use of RAPDPCR and their genetic profiles from different ruminant hosts were compared.

Pairwise comparisons were used to evaluate sequence homology and diversity of some variable regions was identified. Interspecific variation in the regions exceeded that within species. Comparison between Toxocara vitullorum from cattle and Toxocara vitullorum from buffaloes revealed genetic polymorphism with genetic variability observed in DNA amplification with primer 3 and non-genetic polymorphism with genetic variability in primer 1 and primer 2 as displayed in figures

The use of the Random Amplified Polymorphic DNA - Polymerase chain reaction (RAPD-PCR) technique to amplify short regions of an organism's genome provide more specific method than conventionally employed in epidemiological studies.
\end{abstract}

Keywords: Nematodes, Ruminants, RAPD-PCR, Molecular Diagnosis.

\section{Introduction}

Parasitic gastroenteritis caused by parasitic nematodes, is of major concern to ruminant industry and threatens sustainability. Traditional methods for diagnosis of the type and level of infection in a sheep flock require laborious laboratory extraction, culture and microscopic examination of eggs or larvae from fecal samples. Advances in molecular technology offer the potential for more efficient and reliable methods [1], [2].

The utilization of molecular biology techniques brought new approaches for diagnosis of nematodes. Methods to extract DNA of different forms of parasites in fecal samples of animals [3] have allowed the use of molecular tools for the diagnosis of several organisms. With the application of the polymerase chain reaction (PCR) it was possible to extend these studies. The PCR technique has been used to detect DNA of diverse organisms, facilitating the biological diagnosis of the parasites in tissues and secretions. Through PCR technique were able to genetically differentiate Haemonchus contortus from Haemonchus placei [4].

The use of this technique for the investigation of DNA of Echinococcus multilocularis in fecal samples of fox [5] allowed sensible and specific diagnosis for infections caused by this parasite. The amplification of DNA of Trichinella spiralis in larvae encysted in human host muscles or experimentally infected mice, and the identification of different isolates of this helminthes, are advantages provided by this technique [6].

Interspecies diagnostic based on molecular biology techniques are very helpful in the identification \& diagnosis of different species [7]. A variety of molecular methods have been developed but still of limited use to detect and identify helminthes from different population/hosts. Ribosomal DNA sequences are the most common molecular markers were used in differentiation of the nematode species [8]. This fragment of nucleic acid consists of small ribosomal subunit 
DNA (SSU rDNA), large ribosomal subunit DNA (LSU rDNA), two internal transcribed spacer (ITS), and two external transcribed spacer (ETS) [9], [10], and [11]. Nowadays, molecular diagnostic is the common, time/cost effective method used all over the world to interspecies differentiation [2], [12].

\section{Materials and methods}

\subsection{Worm recovery}

Standard procedures were employed to recover worms from the gastrointestinal tract of slaughtered cattle, buffaloes, sheep and goats. Small and large intestines and abomasums were examined for recovery of nematodes [13].

Morphological description and identification of the collected worms were done on mounted specimens. Identification of the adult nematodes worms carried out according to the keys illustrated [13, 14].

\subsection{RAPD-PCR}

The Random Amplified Polymorphic DNA - Polymerase chain reaction (RAPD-PCR) technique is used to amplify short regions of an organism's genome.

Ten different nematode worms were tested with RAPD PCR. Which were Haemonchus contortus, Ostertagia ostertagi, Trichuris ovis, Cooperia curticei, Strongyloides papillosus larvae, Nematodirus sp. Larvae and Haemonchus contortus larvae recovered from sheep and Trichuris ovis from goats. Toxocara vitullorum recovered from cattle and Toxocara vitullorum from buffaloes. The recovered worms were washed several times with PBS and then preserved in $2 \mathrm{ml}$ microfuge tubes (Eppendorf, Germany) that stored at $-20^{\circ} \mathrm{C}$ till further use.

Three primers were tested. The Oligonucleotide sequences of primers were primer 1 (p1) 5' - TCGCGAATTC- 3', primer 2 (p2) 5'-AACGCGCAAC- 3' and primer 3 (p3) 5'- AAACGGTTGGGTGAG- 3'

DNA of nematode worms was extracted by using QIAamp DNA Mini Kit-50 (Cat. No. 51304) according to manufacturer's instructions. DNA quality was checked by electrophoresis on $1 \%$ agarose gel. Extracted DNA samples were tested in $25 \mu \mathrm{l}$ reaction volume in $0.5 \mathrm{ml}$ Eppendorf tubes [15] and were mixed with PCR reagents. The PCR reactions were carried out in Thermocycler (iCycler®, Bio-Rad, Muenchen, Germany) for 45 cycles. Each cycle consisted of 1 minute denaturation at $94 \dot{\mathrm{C}}, 1$ minute annealing at $35 \dot{\mathrm{C}}$ and 2 minute extension at $72 \dot{\mathrm{C}}$. after the last cycle, there was a 5 minute extension at $72 \dot{\mathrm{C}}$. PCR products were checked by electrophoresis on $1 \%$ agarose gel with ethidium bromide and visualized under UV transilluminator (TFX-20M, Viber Lourmat, France).

\section{Results}

PCR conditions of the 10 nematode samples were checked with 3 different primers and the genetic profiles of different nematodes spp. from different ruminants were compared. The RAPD-PCR analysis indicated polymorphism with the used primers (Fig 1).The quality and quantity of extracted DNA from samples were displayed in Fig.1.

RAPDs-PCR analysis of P1 5' - TCGCGAATTC- 3'yielded only one fragment (1300 bp) with Trichuris ovis recovered from goats (Fig.1).

P2 5'-AACGCGCAAC- 3' (Fig.1) yielded one fragment (1100 bp) with Toxocara vitullorum from buffaloes and Toxocara vitullorum from cattle. Also, 5 fragments (900, 1000, 1100, 1200 and $1400 \mathrm{bp}$ ) obtained with ovine Trichuris ovis and no fragments with caprine Trichuris ovis. P2 yielded 3 fragments (900, 1100 and 1200 bp) with ovine Cooperia curticei and 4 fragments (800, 900, 1000 and $1100 \mathrm{bp}$ ) with ovine Nematodirus fillicollis larvae. The RAPDPCR analysis using P2 yielded one fragment (1100bp) with Toxocara vitullorum from cattle and the same with that species from buffaloes

The RAPD-PCR analysis using P3 (Fig.1) yielded one fragment (400 bp) with Toxocara vitullorum from buffaloes and 3 fragments (400, 600 and 1300 bp) with Toxocara vitullorum from cattle. Also P3 yielded 3 fragments (700, 800 and $900 \mathrm{bp}$ ) with ovine Haemonchus contortus and one fragment (1000 bp) with ovine Ostertagia ostertagi. P3 yielded 3 fragments (700, 900 and 1000bp) with ovine Trichuris ovis and only 2 fragments (900 and 1000 bp) with caprine Trichuris ovis.

P3 yielded 5 fragments (500, 600, 800, 900, and $1100 \mathrm{bp}$ ) with ovine Cooperia curticei, 2 fragments (800, 1000 bp) with ovine Nematodirus fillicollis larvae and 4 fragments (700, 800, 900, 1000 and 1100 bp) with ovine Haemonchus contortus larvae. There was no fragment recorded with The RAPD-PCR analysis using P1, P2 and P3 with ovine Strongyloides papillosus larvae as showed in Fig.1 (A, B and C).

Comparison between Toxocara vitullorum from cattle and Toxocara vitullorum from buffaloes revealed genetic polymorphism with genetic variability observed in DNA amplification with primer 3 and non-genetic polymorphism with genetic variability in primer 1 and primer 2 as displayed in Fig.1 (A, B and C). 


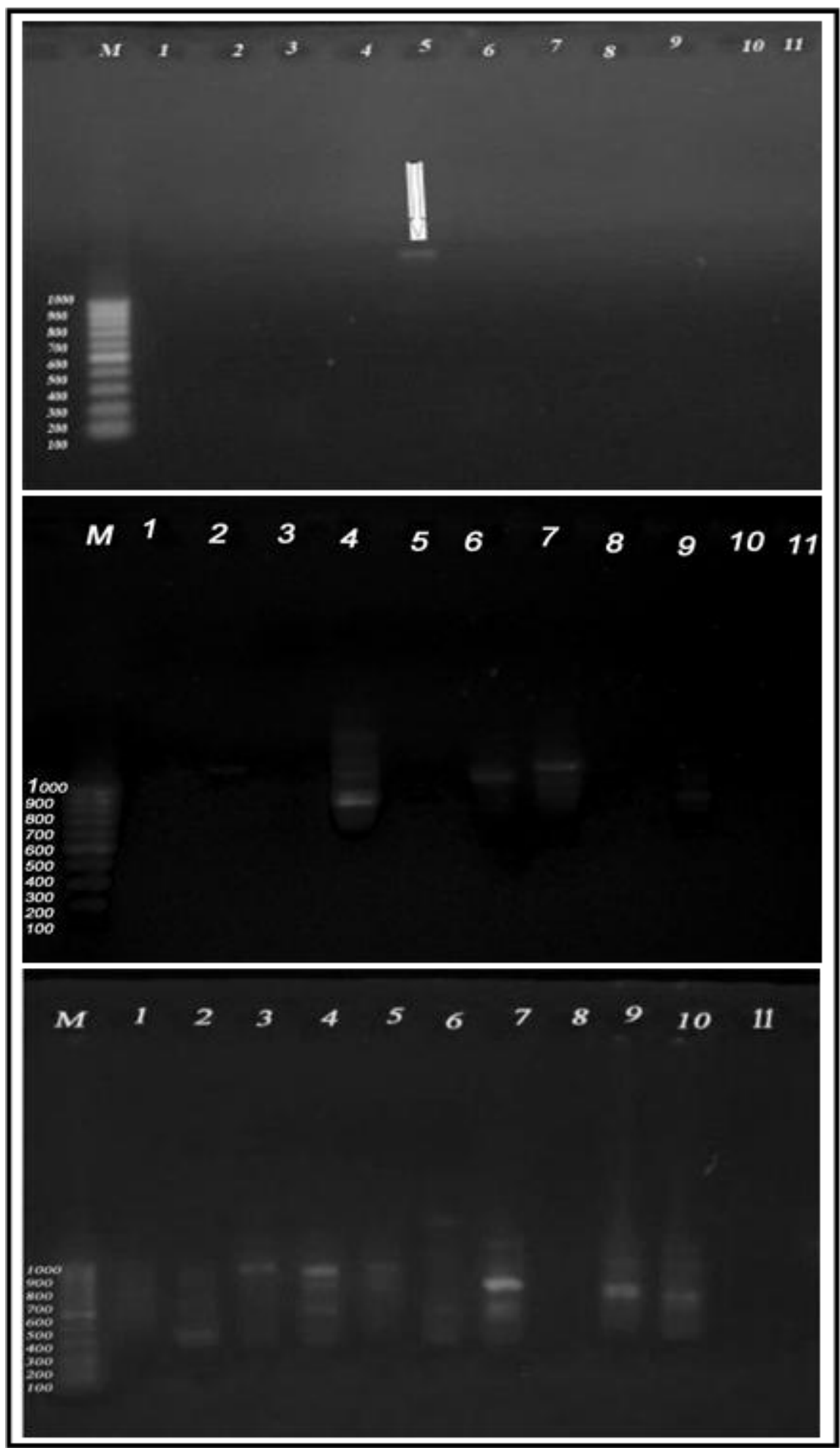

Fig. 1: DNA Amplification Fragments Obtained By Rapds-PCR Using Primer 1 (A), Primer 2 (B) and Primer 3 (C) Analysed By Electrophoresis in 1\% Agarose Gel which was Stained with Ethidium Bromide, M Is for DNA Marker; Lane1 Is for Ovine Haemonchus contortus; Lane2 Is For Toxocara vitullorum From Buffaloes; Lane3 Is for Ovine Ostertagia ostertagi ; Lane4 Is for Ovine Trichuris Ovis; Lane5 Is for Caprine Trichuris ovis; Lane6 Is for Toxocara vitullorum from Cattle; Lane7 Is for Ovine Cooperia curticei; Lane8 Is for Ovine Strongyloides papillosus Larvae ; Lane9 Is for Ovine Nematodirus fillicollis Larvae; Lane10 Is for Ovine Haemonchus contortus Larvae and Lane11 Is for Negative Control

\section{Discussion}

Molecular techniques are utilized for the diagnosis of parasitic diseases and identification of parasites, for the development of specific antigens for serological tests and studying immune response in the patients. Molecular techniques have become widely accepted in the world. They provide more specific method than conventionally employed in epidemiological studies [9]. 
Interspecies diagnostic based on molecular biology techniques are very helpful in the identification \& diagnosis of different species. A variety of molecular methods have been developed but still of limited use to detect and identify helminthes from different population/hosts. Ribosomal DNA sequences are the most common molecular markers were used in differentiation [9], [10], [11], [16], [17]. This fragment of nucleic acid consists of small ribosomal subunit DNA (SSU rDNA), large ribosomal subunit DNA (LSU rDNA), two internal transcribed spacer (ITS) and two external transcribed spacer (ETS) [2].

The use of the Random Amplified Polymorphic DNA - Polymerase chain reaction (RAPD-PCR) technique to amplify short regions of an organism's genome without prior sequence information has great potential in identifying genetic markers, tagging genes and chromosomes, performing population studies and as valuable source of species-specific DNA fragments which may be used as diagnostic probes among organisms and consequently assist in determining their genetic relatedness

In the present study, nematodes species which were Trichuris ovis recovered from goats Trichuris ovis, Haemonchus contortus, and ovine Strongyloides papillosus from sheep. Toxocara vitullorum were from buffaloes and Toxocara vitullorum from cattle. All samples were checked with 3 different primers by the use of RAPD-PCR. The genetic profiles of all nematodes spp. from different ruminant hosts were compared.

The RAPD-PCR analysis indicated polymorphism using P1 yielded only one fragment with Trichuris ovis recovered from goats. While it yielded no fragments with other tested nematode species including Haemonchus contortus. These results disagreed with [18] who recorded that RAPD-PCR analysis using the same primer P1 yielded 8 fragments with Haemonchus contortus this may be due to Genetic polymorphism with genetic variability in Haemonchus contortus. $\mathrm{P} 2$ yielded one fragment with Toxocara vitullorum from buffaloes and Toxocara vitullorum from cattle without Genetic polymorphism. P3 yielded one fragment with Toxocara vitullorum from buffaloes and 3 fragments with Toxocara vitullorum from cattle. There were no fragments recorded with The RAPD-PCR analysis using P1, P2 and P3 with ovine Strongyloides papillosus.

Comparison between Toxocara vitullorum from cattle and buffaloes revealed genetic polymorphism with genetic variability observed in DNA amplification with primer 3 and without genetic polymorphism with genetic variability in primer 1 and primer 2 .

There was a genetic polymorphism with genetic variability observed in DNA amplification with primer 1 primer 2 and primer 3 in between Trichuris ovis recovered from sheep and that recovered from goats revealed

Pairwise comparisons were used to evaluate sequence homology and diversity. Some variable regions were identified. Interspecific variation in the regions exceeded that within species. In order to decide if the morphologically similar species from the two separate host groups (cattle and buffalo) (sheep and goats) should be considered as one species, data from within and between species comparisons were analyzed. Homology was quite high within species, but much lower among the different species; similarly, divergence was low within same species,

The average sequence divergence between similar organisms from different hosts are all in the range of the same species, in contrast, lower than that from different species.

Comparisons between the morphologically similar species showed lower levels of sequence divergence than those between different spp. This observation supports by [19].

However, there was a minimal variation among individuals from one species and morphologically similar species, but their variations were observed to be lower than that from different species [20].

T. vittlorum DNA produced better fragments with primer 2 and with primer 3 than with other primers. The strong DNA bowel on the gel with was observed using primer 3 . The same primers did not produce any amplified products for Strongyloides papillosus and Suitable fragment were obtained from $H$. contortus with $\mathrm{p} 2$.

The present study concluded that RAPD-PCR technique is capable of explaining the genetic relation species ship between nematode spp. infecting cattle, buffaloes, sheep and goats at species level identification. Three primers were tested and found to be positive for all species and in most cases three or more fragments were observed. RAPD-PCR finger printing method used for detection of nematodes produced different amplified products in different spp. of parasites and their hosts.

It is seemed to be a promising method for nematode spp. identification and diagnosis as well as one method to recognize the definitive host of nematode parasites. This technique may effectively be used for differential identification at species level of nematodes spp. infecting cattle, buffalos, sheep and goats.

\section{References}

[1] J. Demeler, E. Schein, G. von Samson-Himmelstjerna, Advances in laboratory diagnosis of parasitic infections of sheep Veterinary Parasitology (2012) 189, 52-64 http://dx.doi.org/10.1016/j.vetpar.2012.03.032.

[2] K. Stojecki, J. Karamon, J. Sroka, T. Cencek, Molecular diagnostics of Sarcocystis spp. Infections Polish Journal of Veterinary Sciences Vol. 15, No. 3 (2012), 589-596.

[3] E.B. Kia, H. Mirhendi, M. Rezaeian, F. Zahabiun, M. Sharbatkhori, First molecular identification of Sarcocystis miescheriana (Protozoa, Apicomplexa) from wild boar (Susscrofa) in Iran. ExpParasitol 127 (2011) 724-726. http://dx.doi.org/10.1016/j.exppara.2010.11.007.

[4] D.S. Zarlenga, B. Chute, L. Gasbarre and P. Boyd, A multiplex PCR assay for differentiating economically important gastrointestinal nematodes of cattle.Vet. Parasitol. 97(3) (2001) 201-211. http://dx.doi.org/10.1016/S0304-4017 (01)00410-1. 
[5] A. Dinkel, M. Nickisch-Rosenegk, B. Bilger, M. Merli, R. Lucius and T. Romig, Detection of Echinococcus multiloculares in the definitive host: coprodiagnosis by PCR as an alternative to necropsy. J. Clin. Microbiol. 36 (1998) 1871-1876.

[6] I. Nagano, Z. Wu, A. Matsuo, E. Pozio and, Y. Takahashi, Identification of Trichinella isolates by polymerase chain reaction- restriction fragment length polymorphism of the mitochondrial cytochome c oxidase subunit I gene. Int. J. Parasitol., 29 (1999) 1113-1120. http://dx.doi.org/10.1016/S0020-7519 (99)00060-0.

[7] K.C. Ian, A.B. Fontanilla, M. Christopher and A. Wade, The small subunit (SSU) ribosomal (r) RNA gene as a genetic marker for identifying infective 3rd juvenile stage Angiostrongylus cantonensis. Acta Tropica 105 (2008) pp 181-186 http://dx.doi.org/10.1016/j.actatropica.2007.10.007.

[8] Josiana G. Andradea, Alena M. I niguezb, Adriane N. Souzac, Valéria C.L. Marquesc, Gonc, alo A. de Souza Filhoc, Clı́vis P. Santosa, Renato A. DaMattaa Genetic characterization of the blood-sucking nematodes Libyostrongylus dentatus and Libyostrongylus douglassii supports their different evolutionary history. Veterinary Parasitology 193 (2013) 193- 199

[9] S.S. Dahlgren, B. Gjerde The red fox (Vulpes vulpes) and the arctic fox (Vulpes lagopus) are definitive hosts of Sarcocystis alces and Sarcocystis hjortifrom moose (Alcesalces). Parasitology 137 (2010) 1547-1557. http://dx.doi.org/10.1017/S0031182010000399.

[10] B.M. Rosenthal, D.B. Dunams, B. Pritt Restricted genetic diversity in the ubiquitous cattle parasite, Sarcocystis cruzi. Infect Genet Evol 8 (2008) 588-592. http://dx.doi.org/10.1016/j.meegid.2008.04.004.

[11] Z. Xiang, X. Chen, L. Yang, Y. He, R. Jiang, B.M. Rosenthal, P. Luan, S.W. Attwood, Y. Zuo, Y.P. Zhang, Z. Yang, Non-invasive methods for identifying oocysts of Sarcocystis spp. from definitive hosts. ParasitolInt 58 (2009) 293-296. http://dx.doi.org/10.1016/j.parint.2009.03.004.

[12] M.I. Shalaby Ismail and A.M Sayed, Preliminary Molecular Identification of Two Helminthes (Moniezia sp. and Paramphistomum sp.) In the Province of Taif, Saudi Arabia. World Applied Sciences Journal 17 (8) (2012) 986-991.

[13] G.M. Urquhart, J. Armour, J.L. Dunncan and F.W. Jennings, Veterinary Parasitology. 1st Ed., ELBS, Longman, London, UK (1996).

[14] MAFF, Manual of Veterinary Parasitological Laboratory Techniques. Ministry of Agriculture, Fisheries and Food. Reference Book No. 418. Her Majesty`s Stationary Office, London, UK (1986).

[15] Stina S. Dahlgren, BjørnGjerde Genetic characterisation of six Sarcocystis species from reindeer (Rangifer tarandus tarandus) in Norway based on the small subunit rRNA gene Vet Parasitol : 46 (2007) 132-9

[16] S. Dangoudoubiyam, R. Vemulapalli and K.R. Kazacos, PCR Assays for Detection of Baylisascaris procyonis Eggs and Larvae. Parasitol. J., 95(3) (2009) 571-577. http://dx.doi.org/10.1645/GE-1905.1.

[17] G. More', P. Abrahamovich, S. Jurado, D. Bacigalupe, J.C. Marin, M. Rambeaud, L. Venturini, M.C. Venturini, Prevalence of Sarcocystis spp. In Argentinean cattle. Vet. Parasitol 177 (2011) 162-165. http://dx.doi.org/10.1016/j.vetpar.2010.11.036.

[18] C. Rabouam, A. Comes, V. Bretagnolle, J. Humbert, G. Periquet and Y. Bigot Features of DNA fragments obtained by random amplified polymorphic DNA (RAPD) assays. Mol. Ecol., 8(3) (1999) 493-503. http://dx.doi.org/10.1046/j.1365-294X.1999.00605.x.

[19] F. GÜÇLÜ1, R.O.S ALDEM,. And L. GÜLER, Differential identification of cattle Sarcocystis spp. By random amplified Polymorphic DNA Polymerase chain reaction (RAPD-PCR). Revue Méd. Vét.,, 155, 8-9, (2004) 440-444

[20] D.A. Morrison, S. Bornstein, P. Thebo, U. Wernery, J. Kinne, J.G. Mattsson, The current status of the small subunit rRNA phylogeny of the coccidia (Sporozoa). Int. J. Parasitol. 34, (2004) 501-514. http://dx.doi.org/10.1016/j.ijpara.2003.11.006. 